REVISTA ANDALUZA DE ANTROPOLOGÍA.

NÚMERO 2: PATRIMONIO CULTURAL Y DERECHOS COLECTIVOS.

MARZO DE 2012

ISSN 2174-6796

[pp. 25-47]

http://dx.doi.org/10.12795/RAA.2012.i02.02

Fecha de recepción: 10/11/2011

Fecha de aceptación: 20/12/2011

\title{
LA CONCEPCIÓN DEL PATRIMONIO ETNOANTROPOLÓGICO EN GALICIA: VISIONES LEGALES Y PRÁCTICAS INSTITUCIONALES
}

\section{XERARDO PEREIRO PÉREZ}

Universidade de Trás-os-Montes e Alto Douro

\section{Resumen.}

Analizamos en este texto las concepciones legislativas e institucionales del patrimonio etnoantropológico en Galicia, y también algunas de sus políticas y prácticas institucionales, con énfasis para los procesos de politización del patrimonio etnoantropológico por parte de la administración autonómica Gallega (Xunta de Galicia). Pasamos revista a la conversión de la etnografía en "etnográfico", al papel que el "patrimonio etnográfico" presenta en la legislación patrimonial gallega en comparación con el patrimonio arqueológico, arquitectónico y artístico. A continuación, desmenuzamos algunas de las políticas y prácticas institucionales de la Xunta de Galicia en materia de patrimonio etnoantropológico. Nuestra observación se realiza desde tres ventanas: a) la Sección de Etnografía; b) las ayudas a la conservación y restauración de bienes patrimoniales etnográficos; c) algunas políticas de la Xunta de Galicia en materia de patrimonio etnográfico inmaterial. Ya en las conclusiones de nuestro trabajo, interpretamos como el campo del patrimonio cultural etnoantropológico sigue en Galicia una versión 
identitaria folclórica y folclorizante, frente a una visión socio-antropológica periférica. Después y haciendo un esfuerzo de síntesis intentamos explicar las razones de ello y sus significados, para finalmente proponer una nueva visión y mirada del patrimonio etnoantropológico gallego.

Palabras clave: Antropología patrimonial, Galicia, etnográfico, etnoantropológico, legislación, prácticas institucionales.

\begin{abstract}
.
We discuss in this text the legislative and institutional conceptions of ethnoanthropological heritage in Galicia, and some of its policies and institutional practices, with emphasis on the processes of ethno-anthropological heritage politicization by the Galician regional government (Xunta de Galicia). We reviewed the conversion of ethnography in 'ethnographic', the role that the "ethnographic heritage" features in the Galician heritage legislation compared with the archaeological, architectural and artistic. Then, we analyze the policies and institutional practices of the Galician ethnoanthropological heritage concerning. Our observation is made from three windows: a) Section of Ethnography, b) aid to the preservation and restoration of heritage ethnographic c) some policies of the Xunta de Galicia on intangible ethnographic heritage. Since the conclusions of our work, we interpret as in the field of ethno-anthropological heritage in Galicia there is a dominant folk version and folkloristic identity, compared to a socialanthropological vision. After making an effort and try to explain the reasons synthesis of this and their meanings, finally, we propose a new vision and a new look for Galician ethno-anthropological heritage.
\end{abstract}

Keywords: Anthropology and heritage, Galicia, ethnographic, ethno-anthropological, legislation, institutional practices.

\title{
1. INTRODUCCIÓN
}

En textos anteriores (Pereiro, 2008; 2009) reflexionábamos sobre la producción sociopolítica del patrimonio etnoantropológico en Galicia. En este texto parto de aquella reflexión e incido en el análisis de las prácticas políticas institucionales derivadas de las concepciones legislativas. Estas reflexiones son resultado de una experiencia antropológica iniciada a principios de la década de 1990, realizando trabajos de investigación patrimonial y museística para la Xunta de Galicia. También son resultado de un trabajo documental y de archivo realizado en la Sección de Etnografía de la Xunta de Galicia, con el objetivo de investigar el papel de la antropología patrimonial en la administración autonómica gallega. Algunos de los resultados de mis investigaciones han sido publicados previamente y sirven igualmente de sustento o complemento a la reflexión que se sigue (Ver: Pereiro, 1995; 1999b; Pereiro y Vilar, 2002; Pereiro, 2005; 
$2006 a ; 2006 b)$.

Desde mi punto de vista, las estrategias de producción, construcción y objetivación del patrimonio etnoantropológico pueden clasificarse en tres tipos. La primera es investigar sobre la historia del concepto de patrimonio y como se fue redefiniendo a lo largo de la historia. Se encuadrarían aquílos debates sobre la definición del patrimonio como cultural, etnológico, etnográfico o antropológico, pero también sus relaciones con otros tipos como el histórico, artístico y el arqueológico. La segunda perspectiva es la de analizar como algunas tradiciones eruditas (historia, geografía, literatura, folclore...) han reflexionado sobre el patrimonio etnoantropológico y como han ido redefiniendo sus contenidos pero también sus métodos de investigación e intervención. Una tercera perspectiva es analizar los procesos de uso y apropiación del patrimonio etnoantropológico por instituciones, administraciones, organizaciones, asociaciones y otros agentes culturales.

En este texto primaremos esta última perspectiva desde un análisis de la realidad gallega, uno de los locus de trabajo antropológico privilegiado en nuestro camino investigador. Nuestro punto de partida es que Galicia es una zona periférica europea en la cual el moderno discurso antropológico permanece marginal en sus aplicaciones sociales patrimoniales, salvando algunas excepciones (ej.: Museo Etnológico de Ribadavia, Parque Etnográfico de Allariz, Museo de la Limia y otros). Pocos son los actores sociales y políticos que se han apropiado de las teorías, los métodos de investigación antropológica, y los resultados de las investigaciones antropológicas contemporáneas. Es por ello que podemos hablar de una cierta ineficacia simbólica del discurso antropológico moderno, lo que ha provocado la aplicación de modelos y paradigmas obsoletos ya abandonados en otros países.

Nuestra opción por el concepto de patrimonio etnoantropológico lo justificamos en la idea de superación de lo etnográfico como simple contenido u objeto, para desplazar este al análisis antropológico de los procesos socioculturales de construcción de los patrimonios culturales; pero también en la elevación de este tipo de patrimonio al nivel comparativo, teórico-antropológico y de representación de las identificaciones colectivas. Analizaremos con detalle y a continuación estas perspectivas.

\section{LO“ETNOGRÁFICO”FRENTEALO“ETNOLÓGICO”YLO“ANTROPOLÓGICO”}

En Galicia la etnografía se ha convertido en un adjetivo y en un contenido ("lo etnográfico"), y no tanto en un método de investigación antropológica, que es aquello que es para los antropólogos socioculturales. Para verificar esta hipótesis basta observar y analizar la proliferación de museos definidos como "etnográficos" (Pereiro y Vilar, 2002) o también las legislaciones y usos sociopolíticos (Smith, 2006) de lo denominado por muchos "patrimonio etnográfico".

¿Por qué la etnografía se convierte en "etnográfico” en Galicia? Es bien cierto que la 
producción de lo "etnográfico" (adjetivo y contenido) está asociada a una ideología global de retorno a la naturaleza y a los legados del pasado que autores como Leo Marx (1964) denominaron de pastoralismo. Por ello hoy en día podemos hablar de una industria del patrimonio cultural y de políticas de restauración de la naturaleza y de la cultura. En ese proceso de largo alcance, lo "etnográfico" pasa a ser una parte del patrimonio cultural, un tipo o un subtipo que sirve de soporte para representar las identidades en proceso de cambio. Pero paradójicamente en esa conversión pocas veces se reflexiona críticamente sobre ese cambio. Más bien la etnografía se convierte en etnográfico para exotizar, ruralizar, primitivizar y autenticar una serie de elementos culturales refolclorizados y retradicionalizados en la tardomodernidad. Es así como se crean imágenes y discursos políticos folclorizantes de las identidades gallegas.

Pero desde una perspectiva crítica todo el patrimonio cultural puede ser etnografiado y estudiado por antropólogos o con metodología antropológica. Una catedral también puede y es también etnografiada como un espacio sociocultural patrimonial de representación de las identidades. Por ello es discutible la idea de definir subtipos de patrimonio cultural y dejar solamente algún subtipo para ser susceptible de ser tratado con metodología antropológica. Del mismo modo la etnografía, en tanto técnica de investigación-acción social puede ser utilizada por otros investigadores, no estrictamente antropólogos, para trabajar con el patrimonio cultural. Eso sí, desde otras perspectivas teóricas que no las de la antropología, es decir, toda etnografía antropológica está guiada por la teoría antropológica.

El problema en Galicia es que muchas veces se produce lo que podíamos denominar apropiación dealgunos métodos antropológicosy vulgarización dealgunas investigaciones antropológicas ${ }^{1}$. Claro está que este uso técnico de la etnografía presenta limitaciones, dado que la etnografía no es apenas una técnica, sino un método de investigación antropológica que obedece a principios metodológicos, teóricos y epistemológicos propios y específicos de la antropología. Además, utilizar la etnografía como técnica de investigación no quiere decir que hagamos una investigación antropológica, sino que podemos estar haciendo una investigación de otro tipo y desde otra perspectiva disciplinar. Para la antropología la etnografía guía la interpretación cultural (Wolcott, 1993), pero también es cierto que la etnografía utilizada en una investigación antropológica debe estar guiada por teoría antropológica.

Resultado de la anterior reflexión podemos afirmar que es de gran importancia que los antropólogos, especialistas en cultura y patrimonio etnoantropológico, asuman un papel protagonista en la investigación, interpretación y activación de este tipo de patrimonio cultural, pero también en todo patrimonio cultural. De acuerdo con la legislación vigente,

1. Para observar un catálogo y una reflexión sobre la situación de la antropología gallega pueden ver Pereiro (2001). 
el patrimonio etnoantropológico es actualmente un subtipo de una taxonomía legal y administrativa, que debe ser encuadrado como un campo o arena de trabajo profesional, de forma que los antropólogos puedan dar sus mejores aportaciones y desempeños en la construcción cultural del nos-otros. Esto no es un alegato corporativista ni una afirmación del "buenismo" de la antropología, más bien una afirmación del papel socioprofesional que debe tener el antropólogo y de su necesidad social, de cara a trabajar con otros profesionales de manera reconocida, articulada, coordenada e interdisciplinar.

\section{EL PATRIMONIO ETNOANTROPOLÓGICO FRENTE AL PATRIMONIO ARQUEOLÓGICO Y ARQUITECTÓNICO}

En este punto vamos a analizar de qué forma se produce legal y administrativamente lo "etnográfico" en Galicia. Comenzaremos nuestro análisis con una revisión del papel que el "patrimonio etnográfico" presenta en la legislación vigente. Este ejercicio analítico se sustenta en la idea de que toda legislación del patrimonio cultural es una legislación sobre las identidades (Agudo Torrico, 2006), y de esta forma contribuyen para una redefinición de las mismas.

La Ley del patrimonio cultural gallego data del año 1995 y se estructura en once partes: una exposición de motivos y diez títulos. El contenido de los títulos es el siguiente: Un título preliminar con disposiciones generales; el título I es dedicado a las categorías de bienes culturales; el II a la protección y la conservación; el III al patrimonio arqueológico; el IV al patrimonio etnográfico; el V a los museos; el VI al patrimonio bibliográfico; el VII al patrimonio documental y a los archivos; el VIII a las medidas de fomento; y el IX al régimen sancionador.

En el artículo 1 del título preliminar encontramos la definición del patrimonio cultural gallego: "O patrimonio cultural de Galicia é constituído por tódolos bens materiais e inmateriais que, polo seu recoñecido valor propio, deban ser considerados como de interese relevante para a permanencia e a identidade da cultura galega a través do tempo" (Artículo $1.1)$.

Por lo tanto, la ley gallega reconoce elementos materiales e inmateriales en el patrimonio cultural, aunque sin una perspectiva relacional, lo inmaterial es tratado en una categoría separada.

El artículo 1.2. afirma que el patrimonio cultural gallego merece "protección, conservación, acrecentamento, difusión e fomento", así como "investigación e transmisión a xeracións futuras". Es esta una manifestación de objetivos e intenciones, expresados de forma integral, pero como veremos más adelante, con muchos problemas en su concretización.

En su título I, especialmente en su artículo 8, la ley clasifica jerárquicamente el patrimonio cultural en tres categorías de elementos: a) bienes de interés cultural (BICs); b) bienes catalogados; c) bienes inventariados. 
Dentro de los bienes de interés cultural, divide estos en bienes muebles, inmuebles e inmateriales, pero también en monumentos, conjuntos históricos, jardines históricos, sitios o territorios históricos, zonas arqueológicas, lugares de interés etnográfico y zona paleontológica.

En el título IV de la ley, el patrimonio etnoantropológico es denominado como "patrimonio etnográfico" y recibe un tratamiento muy breve, menos de una página (título IV), si lo comparamos con la extensión del tratamiento dado al patrimonio arqueológico (5 páginas), a los museos (3 páginas), patrimonio documental y archivos (3 páginas). Además el patrimonio arqueológico es de los pocos tipos de patrimonio definidos en la ley que ha avanzado más allá de los principios generales y cuenta con un posterior desarrollo legal (Decreto 199/1997 de 10 de julio, DOGA no 150 de 6-08-1997 y DOGA no 213 de 4-11-1997). Esta asimetría en el tratamiento legal y en su desarrollo se convierte en subordinación en la propia ley, así en el artículo 66 se dictamina que el "patrimonio etnográfico" puede verse afectado por lo dispuesto en la ley para el patrimonio arqueológico cuando se trate de "bens de carácter etnográfico que constitúan restos físicos do pasado tecnolóxico, produtivo e industrial galego que sexan susceptibles de seren estudiados con metodoloxía arqueolóxica".

Estamos ante una visión arqueologicista y materialista del patrimonio etnoantropológico que reduce este a objeto-tipo (Pais de Brito, 2006) y legado del pasado, sin lecturas de proximidad, familiaridad, identidades, biografía y cotidianeidad. Este ejercicio retórico legitima en sus prácticas el intrusismo profesional, devorando la propia antropología en sus aspectos metodológicos y tirando por la borda la tan recurrida interdisciplinaridad, pues sin un reconocimiento claro del papel profesional de la antropología, difícilmente se puede hacer interdisciplinaridad.

Y si nos detenemos por un instante en la propia definición de "patrimonio etnográfico", en el artículo 64 se define este por sus contenidos, nunca por su perspectiva disciplinar (antropología) o su especificidad metodológica (etnografía): "Integran o patrimonio etnográfico de Galicia os lugares e os bens mobles e inmobles así como as actividades e os coñecementos que constitúan formas relevantes ou expresión da cultura e modos de vida tradicionais e propios do pobo galego nos seus aspectos materiais e inmateriais".

Es esta una definición ya encontrada en la Ley del Patrimonio Histórico Español (artículo 46) con el cambio de español por "galego" y con la inclusión del término "lugares". El problema es que esta definición plantea nuevos problemas que los legisladores no han resuelto. El primero es la elección del concepto "patrimonio etnográfico" en vez de los más apropiados científicamente de "patrimonio etnológico" y "patrimonio antropológico". El segundo es la imprecisión de los límites y contenidos del concepto de patrimonio etnográfico, lo que motiva una cierta inseguridad jurídica. Ello convierte el concepto en algo muy abierto pero al mismo tiempo volátil y difícil de entender por los legisladores y 
sus destinatarios. ¿Cuáles son los límites de lo "tradicional” para un legislador? ¿Cuáles son las "formas relevantes" y las "expresións culturais tradicionais do pobo galego"? ¿Quién tiene legitimidad para definir estas?

Un problema asociado a la propia legislación es el quehacer con los bienes culturales de este tipo no reconocidos administrativamente como "patrimonio cultural”, ¿Cuál sería la actitud frente a ellos? Para resolver estos problemas la ley gallega nos obliga a recurrir a la legislación española de ámbito estatal, y según la Ley del Patrimonio Cultural Español de 1985, los bienes inmuebles de carácter etnográfico son: "aquellas edificaciones e instalaciones cuyo modelo constitutivo sea expresión de conocimientos adquiridos, arraigados y transmitidos consuetudinariamente y cuya factura se acomode, en su conjunto o parcialmente, a una clase, tipo o forma arquitectónicos utilizados tradicionalmente por las comunidades o grupos humanos" (Artículo 47.1).

La misma ley española define así los bienes muebles de carácter etnográfico: "todos aquellos objetos que constituyen la manifestación o el producto de actividades laborales, estéticas y lúdicas propias de cualquier grupo humano, arraigadas y transmitidas consuetudinariamente" (Artículo 47.2).

Asistimos así a una cierta dependencia de la ley española en la definición específica de algunos bienes etnográficos. Al mismo tiempo, si analizamos otras legislaciones como la urbanística, vemos la asimetría del patrimonio etnoantropológico frente al arqueológico y el arquitectónico. Un ejemplo de ello son las "Normas Subsidiarias e Complementarias de Planeamento Urbanístico" del año 1991 (DOGA no 72, de 16 de abril de 1991), que regían en toda la Comunidad Autonómica gallega. En ellas se declara que los contornos de protección para los elementos "etnográficos" son de 50 metros, pero de 100 metros en el caso de la arquitectura religiosa, civil y militar, y de 200 metros en el caso de restos arqueológicos. Vemos como hay Patrimonios y patrimonios, y como no todos los patrimonios culturales son valorados de la misma forma por las legislaciones vigentes, siendo el patrimonio etnoantropológico considerado como algo menor.

\section{EL PATRIMONIO ETNOANTROPOLÓGICO COMO PATRIMONIO HISTÓRICO Y ARTÍSTICO}

La legislación del patrimonio cultural sobrevalora generalmente las creaciones estéticas extraordinarias y subordina otro tipo de bienes culturales. En Galicia, el patrimonio etnoantropológico es habitualmente interpretado y presentado como si fuese una parte del patrimonio histórico-artístico, destacando la idea de que la cultura es una parte de la historia y del arte, y no al contrario. Si bien no todas las legislaciones del patrimonio cultural asumen la idea de que la historia y el arte hacen parte de la cultura, sí que es la perspectiva más habitual en ellas.

En Galicia, el patrimonio "etnográfico" es presentado las más de las veces como un 
elemento histórico-artístico, neutral e inofensivo, lejos de conflictos y tensiones, pero también como un objeto-tipo y no como un objeto-biografía (Pais de Brito, 2006). De esta forma lo definido administrativamente como "patrimonio etnográfico" es re-presentado como patrimonio histórico-artístico, pero dentro del mismo como si fuesen "artes menores", reproduciendo el esquema dicotómico de alta/baja cultura. Así lo etnográfico es construido y re-inventado como un monumento estetizado que se sacraliza en su función representadora (ej.: el molino como monumento y no como industria y cultura del trabajo; el hórreo como retablo religioso y suvenir). Lo etnográfico es convertido en decoración, cambiando sus valores de uso original por los valores decorativos y mercantiles.

Asistimos en Galicia, al igual que en otros muchos contextos, a un proceso de suvenirización del patrimonio etnoantropológico. Es de este modo como por ejemplo el hórreo gallego, después de proceder a un congelamiento metonímico (Appadurai, 2004) se miniaturiza en plástico o piedra como objeto de degustación o recordación turística. Otro ejemplo de la visión ultraestetizante aplicada al patrimonio etnoantropológico son los ejercicios de descontextualización y representación de objetos agrarios en castillos, torres medievales, "pazos" y casas señoriales (Pereiro y Vilar, 2002). Por toda Galicia la objetivación de la cultura rural se monumentaliza resignificando la misma a través de su re-ubicación en salas nobles de edificios de interés histórico-artístico. Es de esta forma como el patrimonio etnoantropológico se presenta desde una lectura histórica y artística del pasado, pero no desde el análisis de las relaciones entre ese pasado y el presente, ni tampoco de sus cambios estructurales, de forma, función, sentido y significado.

Pensamos que esto sucede por varios motivos. El primero es causado por la propia legislación, que es un mecanismo dominante de resignificación de los patrimonios culturales, y que influencia su selección, conservación, interpretación y valoración. Ello ha sido analizado con más detenimiento más arriba. El segundo motivo es que los seleccionadores y certificadores del interés y valor del patrimonio cultural en Galicia han sido generalmente historiadores da arte, arqueólogos, o arquitectos. Ellos detentan hegemónicamente la autoridad para legitimar los bienes culturales dignos de representar la identidad cultural gallega a través de la conversión de los mismos en patrimonio cultural. Este escenario de culturas profesionales, a la cual el antropólogo suele ser ajeno o muy periférico, prefiere el folclorista u erudito local para certificar, si es necesario, el valor del elemento cultural escogido. Los resultados son la folclorización de la cultura, su esencialización y primordialización, y de este modo se desprende al patrimonio etnoantropológico de su estatuto dinámico, procesual y estratégico.

El tercer motivo es el proceso de mercantilización del patrimonio cultural en general y la maquetación historicista y artística del patrimonio etnoantropológico se concibe como más fácilmente comercializable. La miniaturización, la metacrilatización, la artesanía 
vendida como arte, el tipismo y lo rústico envueltos en papel de regalo son algunos ejemplos de esta mercantilización de tinte historicista.

\section{LA APLICACIÓN DE LA LEGISLACIÓN Y LAS POLÍTICAS INSTITUCIONALES AUTONÓMICAS}

En este apartado queremos incidir en la aplicación de la legislación del patrimonio cultural (Castro Allegue, 2002; Llinares García, 2002), centrándonos en el campo del patrimonio etnoantropológico de Galicia y algunas de las políticas de la Xunta de Galicia. Para ello observaremos en varias ventanas: I) la Sección de Etnografía (Xunta de Galicia); II) las ayudas a la conservación y restauración de bienes patrimoniales etnográficos; III) las políticas de la Xunta de Galicia en materia de patrimonio etnográfico inmaterial.

\section{I}

La Sección de Etnografía de la Xunta de Galicia se creó en el año 1991 en el marco de la "Dirección Xeral de Patrimonio Histórico y Documental", por aquel entonces dirigida por el arquitecto Iago Seara. Estamos en el segundo año del primer gobierno de la era fraguiana (gobiernos autonómicos de Manuel Fraga Iribarne) y el consejero de cultura era el galleguista Daniel Barata Quintáns, quien ejerció su cargo entre 1990 y 1993, y que después se convertiría en asesor especial de Manuel Fraga. El primer responsable administrativo de la sección, que tenía como requisito profesional básico la de arquitecto técnico, fue el polifacético Cesáreo Sánchez (poeta, sociólogo y funcionario de la Xunta de Galicia), quien dio un gran impulso a las actividades de la Sección. Asociada a esta Sección se crea la "Comisión Técnica de Etnografía” por medio del Decreto 41/1992 de 6 de febrero (DOGA n. 33 de 18 de febrero de 1992). Esta comisión nace con la voluntad de asesorar a la Sección de Etnografía en las problemáticas relacionadas con el patrimonio Fetnoantropológico ${ }^{2}$ y será legitimada posteriormente por la ley de patrimonio cultural de Galicia de 1995 en su artículo 7 (órganos asesores y consultores).

La Sección de Etnografía desarrolló principalmente dos líneas de trabajo: a) las ayudas a la investigación del patrimonio etnoantropológico; b) el asesoramiento e informe de proyectos que afectaban algunos elementos patrimoniales. En general podemos afirmar que su trabajo pionero tuvo un carácter heroico pero también algo improvisado debido a que se trabajó sin que el patrimonio cultural gallego tuviese una legislación propia, algo que solamente cambiará en 1995 con la entrada en vigor de la ley del patrimonio cultural gallego. Durante la existencia de esta Sección se desarrollaron tres convocatorias

2. La comisión estaba presidida por el director general de patrimonio y hacían parte de la misma, el subdirector general, el responsable de la Sección de Etnografía (Cesáreo Sánchez), un representante de cada una de las universidades gallegas del "area de estudios antropolóxico-etnográficos", un representante del Instituto Padre Sarmiento (CSIC), un representante del Instituto de Estudios Galegos, un representante del "Museo do Pobo Galego", otro del "Consello da Cultura da Galega" y dos personas de reconocido prestigio. Ver Diario Oficial de Galicia (DOGA) n. ${ }^{\circ} 33$ de 18 de febrero de 1992. 
de ayudas para la investigación de lo que se denominó "patrimonio etnográfico", para cada una de las cuales la Xunta de Galicia destinó aproximadamente 30 de los antiguos millones de pesetas (180.303,63 Euros), lo que suponía aproximadamente una cuarta parte de lo destinado a la investigación en arqueología. En su primera convocatoria se define claramente su orientación conceptual, dando prioridad a: "traballos de inventariado da arquitectura popular... estudios de carácter etnográfio propostos por/ ou concorrentes con plans pilotos ... estudios parciais ou monográficos de proxectos de investigación que, estando xa en curso de realización, precisen dun apoio complementario para a súa conclusión." (Artículo 30 de la Orden del 30-01-1992 para ayudas a trabajos de investigación, inventario e intervención en el patrimonio etnográfico, Diario Oficial de Galicia, 21-02-1992)

Vemos como la investigación se reduce a inventario y clasificación, sin ir más allá de la simple catalogación. En esta política de inventario, a la primacía del patrimonio arquitectónico y material se unen la aplicabilidad o relación con planes "pilotos" que nunca fueron bien conceptualizados. Los equipos de investigación de los proyectos no tenían obligatoriamente que ser integrados por un antropólogo, y el predominio en ellos fue de arquitectos, historiadores del arte y arqueólogos. Esto representa una gran diferencia con otras comunidades autonómicas españolas como Andalucía, que en una convocatoria de la época semejante a la gallega exigía que los solicitantes y los equipos de investigación estuviesen integrados por antropólogos (Ver BOJA n. 28, 16-03-1993). Para la coordinación de la política de inventario se creó una ficha manuscrita, pero no una base de datos o una ficha digital que facilitase su posterior divulgación y uso social (ej. educativo, investigador). La perspectiva teórica de la ficha era fundamentalmente arquitectonicista y arqueologicista, pero también anti-antropológica. Un ejemplo de ello es la creación de subcategorías como la de "construcciones de función no material" en la que se integraban: elementos votivos, construcciones para el culto, recintos de enterramiento. Otro ejemplo es que en el "patrimonio etnográfico mobiliario" se creó la falsa dicotomía de mobiliario para actividades económicas y no económicas. En el "patrimonio etnográfico inmaterial" la literatura de tradición oral, la música y la danza, los juegos y diversiones eran clasificados como "expresiones no rituales". Pero la construcción de esta ficha no fue un proceso pacífico, sino que representó un terreno de lucha teórica entre una visión folclorista y una visión antropológica del patrimonio cultural. Entre los que más cuestionaron constructivamente la propia ficha destacó el catedrático de antropología social de la Universidad de Coruña, José Antonio Fernández de Rota.

En las actas de la Comisión Técnica de Etnografía se encuentran registrados algunos de estos debates, en los cuales se llega a proponer sustituir el concepto de "patrimonio inmaterial" por el de "actividades y conocimientos", defendiendo un concepto 
antropológico holístico e integral de cultura y patrimonio cultural. En total los proyectos de investigación (inventario) presentados a la Sección de Etnografía fueron en sus tres convocatorias los siguientes:

\begin{tabular}{|c|c|c|}
\hline & Solicitudes & Aprobados \\
\hline 1992 & 31 & 27 \\
\hline 1993 & 47 & 35 \\
\hline 1994 & 69 & 37 \\
\hline
\end{tabular}

Tabla n 1: Proyectos de investigación sobre el patrimonio "etnográfico" gallego. Fuente: Dirección Xeral de Patrimonio Cultural (Xunta de Galicia) y elaboración propia.

En su primera convocatoria, la de 1992, los proyectos presentados tenían como objetivo inventariar, en su inmensa mayoría, el patrimonio inmobiliario de zonas consideradas rurales. Sólo un proyecto definió como contexto de investigación las pequeñas ciudades (vilas) de Galicia. Sólo 9 de los proyectos, es decir la tercera parte, integra o aborda el patrimonio inmaterial como problema de investigación. Sólo 3 de los proyectos contemplaban el mundo del mar y las zonas costeras gallegas, en una tierra de más de 1200 quilómetros de línea de costa, algo que constituye una aparente paradoja pero que es bien significativo y revelador del peso de lo "rural" en la definición patrimonial de la identidad colectiva galaica. La cantidad máxima que se atribuyó a cada proyecto fue de 3 millones de las antiguas pesetas (18.030,36 euros) que por aquel entonces significaba mucho más que su traducción actual en euros.

En el año 1993 se abre la segunda convocatoria de ayudas, la tendencia a primar el patrimonio "etnográfico" de tipo arquitectónico continúa y únicamente se apoyan 9 proyectos clasificados como de patrimonio inmaterial. La novedad se produce en el perfil de los solicitantes, pues aumenta algo el número de antropólogos a solicitar estas ayudas. Es la época del primer "Xacobeo" (versión laica del año santo compostelano), invento cultural-comercial de la Xunta de Galicia para aprovechar la celebración del año santo compostelano. En aquella altura se produjeron problemas de atrasos en los cobros de las subvenciones, que según los comentarios informales de los técnicos de la Sección de Etnografía eran debidos a que Julio Iglesias, nombrado embajador del Xacobeo 93, había vaciado los cofres de la Consejería de Cultura. En esa época se revitaliza la ley del $1 \%$ en obras públicas para promoción cultural y el $0.50 \%$ va a ser destinado al Xacobeo. En la convocatoria de 1994, además de continuar a aumentar el número de solicitudes, 
más del doble con relación a la primera convocatoria, también sigue aumentando el número de antropólogos peticionarios, pero las problemáticas de investigación se siguen centrando en el patrimonio inmobiliario y en zonas rurales lejanas de los centros urbanos. Inclusive la comisión técnica llega a definir como no prioritarias las zonas periurbanas de las ciudades gallegas. Esta visión anti-urbana de la investigación antropológica gallega se adaptaba en el fondo a una tradicional división social del trabajo intelectual patrimonial que se ha venido forjando durante décadas en Galicia. Según esta división social intelectual, el universo rural estaría reservado para que los etnógrafos, en el más amplio sentido de la palabra, coleccionasen conocimientos curiosos, raros, ancestrales y exóticos. Por otro lado, el universo urbano sería objeto de atención central de otros científicos sociales. Esta división tiene como base una falsa dicotomía, bastante miope, que ha sido incapaz de ver los procesos de urbanización gallegos como procesos de relación intercultural entre lo urbano (dominante) y lo rural.

Un aspecto que consideramos importante de las convocatorias analizadas es la necesidad de presentar un aval de una institución "etnográfica" que apoye el proyecto de inventario presentado. Lo cierto y llamativo es que se admitieron avales de todo tipo de instituciones, no precisamente antropológicas ni "etnográficas". En algún caso un alcalde llega a avalar un proyecto y este aval es aceptado por la Comisión Técnica de Etnografía. En otro caso un investigador se avala a si mismo. El problema aquí radicó en la disolución de la autoridad antropológica y etnográfica, devorada esta por instituciones que nada tienen que ver con la baja institucionalización de la ciencia antropológica en Galicia.

La Sección de Etnografía desapareció como tal en 1996. Después de una muerte lenta se integró en las Secciones de Arquitectura y Arqueología, confirmando institucionalmente las hipótesis arriba enunciadas sobre la subordinación del patrimonio etnoantropológico ante la arquitectura y la arqueología. Los resultados de los proyectos de investigación e inventario han quedado almacenados sin mayor uso en las dependencias de la Xunta de Galicia en Santiago de Compostela, y aunque algunos investigadores han aprovechado esos trabajos para sus tesis de doctorado, el freno a su desarrollo representó indirectamente un freno al desarrollo de la antropología patrimonial en Galicia, ya con poco espacio en los museos y otras instituciones. Tenemos que decir también que la política de inventarios ha conducido a una situación de hipostasia de los bienes culturales patrimoniales de tipo material. Además de los BICs genéricos de tipo etnológico (ej.: hórreos, "cabazos", "petos de ánimas" y cruceros de más de cien años de antigüedad), los bienes culturales inventariados en los años 1990 han reforzado la imagen arquitectonicista y materialista del patrimonio etnoantropológico gallego.

Sucedió también que el poco tiempo de existencia de esta Sección motivó la falta de articulación entre los diferentes departamentos de la administración pública gallega, algunos de los cuales llegaron a apoyar el mismo tipo de trabajos a otros equipos de 
investigación. Un ejemplo cercano de ello es el "Estudio de Construcción Rural en el Camino de Santiago: Palas de Rei” (Rodríguez Castro-Rial, Sánchez Rancaño y Taboada Acevedo, 1996), publicado por la Consejería de Cultura de la Xunta de Galicia y que coincide en problemática y contexto con el inventario sobre patrimonio "etnográfico" inmobiliario del mismo municipio investigado por este autor (Pereiro, 1993).

En el año 2008, la Comisión Técnica de Etnografía fue reactivada por medio del Decreto 60/2008, de 13 de marzo, por el que se regula la composición y funcionamiento de la Comisión Técnica de Etnografía (DOG de 2 de abril de 2008). Esta comisión depende de la Dirección General de Patrimonio Cultural, pero está aún por ver su labor e impacto. Lo novedoso es que desde el punto de vista conceptual ya se habla de patrimonio etnográfico y antropológico.

Una segunda política a analizar es la de conservación y restauración de bienes culturales etnoantropológicos, que tiene sus antecedentes en la década de 1990, durante la época de gobiernos del PP (Presidentes Gerardo Fernández Albor y Manuel Fraga). En los años 1990 esta política fracasó en parte, es decir, no se consiguió el efecto esperado de conservación, restauración y rehabilitación, a pesar del gran número de solicitudes. Entre los motivos del fracaso destacaron la obligación del propietario del bien en coparticipar con un porcentaje elevado de inversión económica en la restauración del mismo. Los bienes a los cuales se destinaban estas ayudas eran arquitecturas como los hórreos, los molinos y los hornos.

Esta política será retomada en la primera década del siglo XXI. Una orden del 24 de mayo del 2007 publicada en el Diario Oficial de Galicia (DOG nº 105 de 1-07-2007) establece las bases reguladoras de las ayudas a la "conservación e a restauración de bens do patrimonio etnográfico de Galicia". Estas bases son muy semejantes a las anteriores promovidas en los años 1990 y en ellas se reconoce el "ámbito etnográfico" como parte del patrimonio cultural gallego y se integran en el mismo los hórreos, los cruceros, los "petos de ánimas", los molinos, los lavaderos, los hornos, los palomares, los pajares, las pallozas... que hagan parte del Inventario General del Patrimonio Cultural de Galicia. Es decir, se destaca nuevamente el patrimonio cultural inmueble y se le aplica una visión arquitectonicista ruralista. La única excepción a esa visión ruralista es la introducción de una tercera categoría de elementos etnográficos, que se añaden a las anteriores de bienes de interés cultural (BIC) y bienes inventariados, en la que se incluyen bienes culturales de tipo etnográfico del contorno de los conjuntos históricos y del Camino Francés de Santiago de Compostela: "Aquellos elementos que constituyan el patrimonio etnográfico, como los referidos en el apartado b) anterior, pero que, sin estar inventariados de manera individual, formen parte del entorno delimitado de los conjuntos históricos, de los lugares de interés etnográfico o de los monumentos declarados BIC, así como en el 
territorio histórico del Camino de Santiago (Camino Francés), siempre que conserven sus características constructivas esenciales y definitorias originales, su fisonomía y el carácter tradicional, así como una vinculación con su ámbito inmediato" (DOG no 105, 1-06-2007, artículo $5 \mathrm{c}$ ).

Esta política se desarrolla en un tiempo político dominado por el gobierno bipartito entre el PSG-PSOE (Partido Socialista) y el BNG (Bloque Nacionalista Galego), y recupera una acción política de la época anterior con gobiernos del PP. Este tipo de patrimonio etnoantropológico parece materializar, visibilizar y objetualizar más fácilmente y con más eficacia simbólica las identidades (Handler, 1988) gallegas. La fuerza de los símbolos identitarios parece condensarse mejor en este tipo de materializaciones de la cultura gallega.

Los resultados de esta política en el año 2007 fueron cerca de 800 peticiones, de las cuales se han aprobado 239 proyectos (fuente: Dirección Xeral de Patrimonio Cultural), lo que demuestra el interés creciente en Galicia por este tipo de patrimonio cultural. Pero de los proyectos aprobados, las ayudas que se han adjudicado han sido solamente 107 (fuente: Xornal de Galicia, 10-04-2008).

En el año 2008 (Orden del 31-03-2008) se siguió con esta política a la cual se destinaron 300.000 Euros. Las ayudas atribuidas llegaban hasta un $60 \%$ del coste total del proyecto (máximo de 2000 Euros para conservación y de 6000 para restauración). Como podemos ver en alguna relación de beneficiarios (Resolución de 15-10-2008, DOG n 248, 23-122008, pp. 22954-22955), las ayudas se destinaron en su inmensa mayoría a la recuperación de hórreos, con importes variables desde 1680 a 6000 Euros cada uno.

En el año 2009, y ya entrado el actual gobierno del PP (Presidente Alberto Núñez Feijóo), se continuó con esta acción política (ver DOG, 13-04-2009, orden 3-04-2009) un año más, que sirvió para restaurar más hórreos y arquitecturas tradicionales rurales (Ver DOG no 222, 12-11-2009, p. 17535; Resolución del 25-09-2009), pero posteriormente esta política fue paralizada.

\section{III}

Otro ejemplo para la reflexión es la política de patrimonio inmaterial autonómica, que por primera vez fue impulsada, de forma específica, durante el gobierno bipartito gallego (PSOE - BNG) del 2005 al 2009, dirigida desde la "Consellería de Cultura e Deporte", y siendo consejera la bióloga de formación y política del BNG (Bloque Nacionalista Galego), Anxela Bugallo.

La primera nota sobre esta línea de acción política es su novedad, porque anteriormente no se había tenido en cuenta o se había dejado muy en un segundo plano; la segunda es relativa a la estructura de organización política de la propia consejería, pues se segmentaron en dos departamentos las responsabilidades de las políticas de patrimonio 
cultural material e inmaterial. El primero pasó a ser responsabilidad de la "Dirección Xeral de Patrimonio Cultural” (dirigida por el arqueólogo y museólogo Felipe Arias Vilas) y el segundo de la "Dirección Xeral de Creación e Difusión Cultural" (dirigida por el geógrafo de formación Luis Bará). Esta visión dicotómica poco integral y poco holística, impulsó un conjunto de líneas de trabajo y acciones directamente relacionadas con el patrimonio etnoantropológico, entre las que destacamos:

a) El proyecto "Ronsel", promovido por tres consejerías de la Xunta de Galicia y realizado en cooperación con las tres universidades gallegas, bajo la coordinación de la Universidad de Vigo, ha tenido como objetivo crear un plan estratégico para el patrimonio etnográfico inmaterial y realizar un inventario del patrimonio cultural inmaterial gallego. El plan estratégico ha sido dirigido por el catedrático de matemática Iván Area (Area, 2008) y ha contado con un presupuesto de 520.455 Euros (ver: http://webs.uvigo.es/ronsel/ ).

b) Apoyo a la candidatura a patrimonio inmaterial de la humanidad de la cultura gallego-portuguesa, promovida por la asociación pedagógica "Ponte nas Ondas" (ver www.pontenasondas.org) desde el año 2005.

c) Semana de la literatura de tradición oral (del 6 al 12 de noviembre de 2006), promovida por la "Dirección Xeral de Creación e Difusión Cultural”. (Ver: www. pontenasondas.org).

d) "III Xornadas sobre protección do patrimonio cultural", encuentro con jueces y fiscales, dedicado a la legislación del patrimonio etnoantropológico (14 y 15 de junio de 2007).

En estas prácticas políticas podemos encontrar una revisión de las agendas del patrimonio etnoantropológico en su concepción y acción. Pero al mismo tiempo también hay que subrayar en estas políticas y sus desarrollos la tensión entre una visión folcloricista del patrimonio etnoantropológico, y otra visión de concepción socio-antropológica (Pereiro, 1999a). La primera presenta una concepción esencialista de la cultura gallega y un pequeño ejemplo de ella es el texto de presentación de la "Semana de Literatura de Tradición Oral":

"A historia da sociedade galega e da súa lingua produciu un inmenso tesouro de composicións narrativas ou líricas de fondas raíces, que pertencen ao pobo, que as creou para sempre... nos que a participación e a relación humana manteñan a esencia dese legado, que se basea no estabelecemento de vencellos emocionais e solidarios dos elementos que constrúen a cultura popular".

La visión folclorista tiene como discurso la pérdida de la tradición y la urgencia de su rescate y salvaguarda, sin cuestionar críticamente que algunas pérdidas culturales nos pueden enriquecer (ej.: la violencia de género). La visión folclorista confunde cultura 
con identidad, y costumbres del pasado con tradición, al mismo tiempo que reduce lo etnográfico a ruralismo y pre-industrialismo. Frente a esa visión y en las acciones referidas más arriba, la visión antropológica se ha centrado en:

a) Dar valor a los usos, funciones, significados, sentidos y procesos sociales de patrimonialización frente a la simple conservación de edificios y contenedores.

b) Incorporar los valores etnoantropológicos a otros tipos de patrimonio.

c) Relacionar lo material con lo inmaterial.

d) Vincular una actividad a personas, espacios y estructuras sociales.

e) Biografiar lo objetual y personificar lo material de la cultura.

f) Defender la investigación y la documentación como mejor forma de "conservar" el patrimonio cultural.

g) Introducir las teorías y los métodos antropológicos modernos en el campo del patrimonio cultural.

h) Valorizar los productores culturales de la misma forma que los productos y contenidos culturales.

Claro está que estas dos visiones debaten en los escenarios de lucha arriba referenciados y también en otros, destacando la visión folclorista y folclorizante sobre la marginal visión antropológica.

\section{EL PATRIMONIO ETNOANTROPOLÓGICO CONTRA LAS IDENTIDADES}

Los antropólogos solemos afirmar que el patrimonio cultural es una determinada representación de las identidades que maneja símbolos con el objetivo de afirmar una determinada identificación. Pensamos que en el campo del patrimonio cultural etnoantropológico gallegola versión identitaria que predomina actualmente es la folclórica y folclorizante. Esta versión se apoya en un pilar fundamental de la cultura gallega: los discursos identitarios construidos por la Generación Nós y el Seminario de Estudios Gallegos (Medeiros, 2006). Si bien en su época (años 1920 y 1930) podríamos considerar sus discursos y prácticas como vanguardistas para su época, hoy en día su perpetuación se ha enmascarado de un esencialismo de tinte folclorista y re-tradicionalizador.

Si el nacionalismo gallego recurrió desde sus orígenes a la historia y a la antropología para sustentar la diferencia cultural gallega (Medeiros, 2006), durante el período autonómico, pero especialmente durante la época de los gobiernos de Manuel Fraga, la cultura y los modos de vida gallegos fueran considerados de tal forma (Méndez, 2004), que en su conversión en patrimonio etnoantropológico se han querido representar como parte destacada del cuerpo nacional español. En ese proceso se ha desdibujado la antropología y se ha despojado al patrimonio etnoantropológico de sus correspondientes análisis 
de las estructuras sociales y de los procesos de transformación social, para re-crear una identidad mítica y monolítica. El objetivo era reafirmar que los gallegos éramos españoles en nuestra diferencia, pero también europeos y universales, y también mansos, conservadores, rurales y tradicionales.

Es de esta forma que podemos afirmar que muchos procesos de patrimonialización etnoantropológica anularon en sus representaciones la pluralidad de identidades, y redujeron las identidades gallegas a rural y agraria, sin reflexionar sobre las relaciones con el mundo urbano, la integración en la economía de Mercado y en el marco del Estado español y de la Unión Europea. Lo urbano es considerado menos relevante y menos expresivo de los "modos de vida tradicionais do pobo galego" como lo demuestra el hecho que los únicos "lugares de interés etnográfico" sean tres contextos rurales (aldea de Seceda de Caurel, Molinos de Folón y aldea de Froxán).

El patrimonio etnoantropológico es reducido a lo que el antropólogo Xosé Carlos Sierra (2000: 416-420) denomina como "iconografía vulgarizada de lo etnográfico", es decir a: aldeas, molinos, hórreos, "petos de ánimas", aperos agrícolas manuales. Esta construcción de lo "etnográfico" silencia los conflictos de identidades y entre identidades, asociándose al ruralismo y una creación imaginaria de la "autenticidad" perdida. Paradójicamente quienes promueven estos procesos de patrimonialización (Pereiro y Vilar, 2002) suelen ser urbanos que encuentran en lo "rural" una representación más apropiada y genuina de la identidad gallega. Es de esta forma como muchos agentes patrimonializadores neutralizan, idealizan, estatizan y despojan de memorias críticas a los elementos escogidos, convirtiendo estos en neutrales e inofensivos.

Así se patrimonializa para olvidar, pues aunque en teoría se activen memorias, lo que en realidad se produce es una selección rupturista con el pasado histórico. En Galicia se produjo una quiebra entre patrimonio cultural y memorias (Sierra, 2006) pero también un proceso político de amnesia institucionalizada (Bennet, 1995). Muchas memorias se vaciaron de contenido y se silenciaron con el objetivo de crear arcadias felices para el turismo. Esta hiperidealización utilizó métodos y teorías anti-antropológicas que situaron algunas versiones de las identidades gallegas en un escaparate de relaciones local-global. Se ocultaron entre otras las condiciones de dominación, las resistencias, la dureza de las culturas del trabajo y los contactos entre lo rural, lo urbano y lo marino.

En estas patrimonializaciones siempre se produce una tensión entre permanencia y continuidad, pero pocas veces estarán presentes los discursos antropológicos de la innovación, el cambio social, la urbanización y la industrialización, pues fueron considerados menos "tradicionales" y menos relevantes en la definición de las identidades gallegas. En los procesos de patrimonialización se materializará la cultura de forma objetual y no sujetual, dando realce al objeto artesano y a la arquitectura en si, pero nada o muy poco se hablará del artesano o de los habitantes de una vivienda. Perspectivas 
antropológicas como el género o la interculturalidad (Appadurai, 2004) pocas veces estarán presentes, y mucho menos la emigración como estrategia de reproducción social.

En resumen, en Galicia pocas veces se patrimonializa el patrimonio etnoantropológico teniendo en cuenta las modernas teorías antropológicas y sus investigaciones (Pereiro y Vilar, 2002). De este modo el patrimonio etnoantropológico anula la pluralidad de identidades que la ha conformado y significado, reconstruyendo lo exótico de aquí y lo típico de dentro en una nostalgia por una arcadia perdida. Todo ello es condicionado y reforzado por la legislación del patrimonio cultural y algunas prácticas institucionales autonómicas analizadas más atrás.

\section{POR UNA NUEVA VISIÓN DEL PATRIMONIO ETNOANTROPOLÓGICO}

"Muitos profissionais da cultura, aqueles que vivem dela sem necessidade de a estudar ou de se preocuparem com o seu funcionamento, acabam por nos vencer, a nós que nos dedicamos a investigá-la profissionalmente. Encontram-se geralmente mais próximos do poder e, como tal, são muito mais confortáveis e simpáticos para os seus detentores: não colocam questões, não discutem terminologia, não constroem e desconstroem conceitos, não se detêm em matizes. E vendem-se barato, ainda que, logo a seguir, cobrem em géneros ou produtos derivados" (Diaz Ga. Viana, 2006: 157).

Desde nuestro punto de vista, la antropología patrimonial debe ser central en los debates sobre el patrimonio etnoantropológico, continuando e intensificando las investigaciones, aplicaciones e intervenciones en el patrimonio etnoantropológico ya realizadas en el contexto gallego por los antropólogos ${ }^{3}$.

A lo largo del tiempo, la antropología ha sido fundamental en la creación de la genealogía del nosotros, pero también y sobre todo en la interpretación y comprensión de los textos y contextos sociales del patrimonio cultural. La antropología, y en particular la antropología patrimonial (González Alcantud, 2003) se presenta así como una alternativa a la folclorización patrimonial. Desde una antropología patrimonial proponemos un giro etnográfico del patrimonio (Fernández de Rota, 2009) o un giro antropológico en la producción de patrimonio etnoantropológico gallego (Pereiro, 2006).

En primer lugar proponemos una redefinición teórica y legislativa de este tipo de patrimonio, algo muy necesario en este momento de oportunidad, al estar a formularse una nueva ley del patrimonio cultural de Galicia. Para eso es necesario repensar los límites y contenidos de este tipo de patrimonio cultural, ya de por sí difícil de delimitar,

3. Por citar sólo algunos autores podemos destacar a José Antonio Fernández de Rota (D.E.P.), Xosé Carlos Sierra Rodríguez, Nieves Herrero, Antonio García Allut, Luis Gárate Castro, José María Cardesín, Miguel Martínez López, Manolo Vilar, Fátima Braña, Eva Mouriño, Xosé Manuel González Reboredo, Santiago Prado Conde, Sharon Roseman, Marcos Gallego, Luzía Oca y Paulo Jablonski entre otros. Obras antropológicas más recientes, en las cuales se reflexiona sobre antropología patrimonial son Pereiro Pérez Xerardo (2005), María Jesús Pena Castro (2006), Sharon R Roseman (2008). 
pero también los criterios, procesos y objetivos de reconocimiento patrimonial. Esta redefinición legal pasa por vincular lo material con lo inmaterial, la cultura con la naturaleza, adoptando las modernas teorías antropológicas como centrales.

En segundo lugar proponemos situar la investigación antropológica en el centro del debate y de las políticas de patrimonio cultural ${ }^{4}$, recuperando al mismo tiempo la autoridad antropológica en su relación con el patrimonio cultural, no apenas con el etnoantropológico. Galicia presenta en este campo un déficit con relación a otras zonas europeas que debe ser colmatado por medio del protagonismo antropológico y su incidencia en las políticas públicas. Desde nuestra perspectiva, las acciones patrimoniales deben ser vinculadas con las necesidades de las poblaciones, y para ello la antropología y los antropólogos estamos especialmente preparados.

Si esto no se produce corremos el riesgo de perder más patrimonio cultural del que conservamos, y lo que es peor aún, de perder el conocimiento de los sistemas socioculturales, los bienes culturales y sus conocimientos locales asociados. Una política centrada en la investigación del patrimonio etnoantropológico y no sólo en su inventario, permitiría crear instrumentos de desarrollo comunitario, educación e interpretación patrimonial, articulando estos con la política de museos. Esta política debería servir para ayudar a resolver los problemas del presente y del futuro, comprendiendo y conectando las diversidades en la realidad cultural gallega: la Galicia urbana con la rural y rurbana, la Galicia administrativa con la Galicia de la emigración, Galicia con los países y territorios vecinos de Asturias, León y Portugal; la cultura gallega con las otras culturas que recibimos y nos enriquecen (ej.: caboverdianos, latinoamericanos...).

Y esta nueva visión del patrimonio etnoantropológico tiene que pasar necesariamente por la creación de una licenciatura en antropología sociocultural y un máster en patrimonio

4. Se prepara en estos momentos una nueva ley del patrimonio cultural gallego, siendo uno de sus responsables el fiscal de patrimonio cultural de Galicia, Antonio Roma, quien con su labor fiscal snacionadora y pedagógica ha hecho cambiar la percepción social del patrimonio cultural en Galicia. Sin embargo, las políticas del patrimonio cultural en Galicia están condicionadas económicamente por el polémico proyecto de la Ciudad de la Cultura Gallega, un proyecto promovido por el gobierno de Manuel Fraga en el año 2001, que está situado en el Monte Gaiás de Santiago de Compostela bajo el diseño de "Eisenman arquitects". Este proyecto fue redefinido por el gobierno bipartito (PSOE-BNG) (2005-2009), quien propuso, entre otras cosas, un "Centro de Investigación del Patrimonio" que quedó de momento en nada. El gobierno bipartito también propuso la creación de una Biblioteca Nacional de Galicia, el Museo de Historia de Galicia, el Centro de Arte Internacional, el Archivo Nacional de Galicia y un "Escenario Obradoiro". El coste del proyecto ya supera los 350 millones de Euros. Fuente: El Correo Gallego, 21-11-2007, p. 19. En enero de 2012, bajo la batuta del gobierno del PP (Presidente Alberto Núñez Feijóo) se encuentran abiertos al público la biblioteca, el archivo y el museo, este último se puede visitar desde noviembre, pero no acogerá exposiciones hasta la primavera. En breve será inaugurado el edificio de servicios centrales y están paralizados, por lo menos hasta 2014, el centro de arte y el centro de música y artes escénicas, con un presupuesto de 175 millones de Euros inasumibles en la situación actual de crisis financiera (fuente: El Progreso, 31-12-2011). 
cultural y museología, que permitan formar profesionales y especialistas bien preparados para trabajar en este campo de acción. Además, esto debe implicar una extensión de la educación patrimonial a la enseñanza primaria y secundaria, incluyendo una materia de antropología que permita comprender mejor la diversidad sociocultural, con la misma importancia que se aprenden los valores de la biodiversidad.

\section{Agradecimientos}

Este texto tiene como base una conferencia pronunciada en las XVI Jornadas Andaluzas de Etnología (Granada, 19-21 de Noviembre de 2007). Agradezco a Esther Fernández Paz la invitación para esas jornadas, los comentarios de los participantes y de los antropólogos Manolo Vilar y Nieves Herrero. La investigación base se encuadra en un proyecto de investigación del CETRAD, un centro de investigación que es financiado por Fondos Nacionales a través de la FCT - Fundação para a Ciência e Tecnologia- de Portugal, en el ámbito del proyecto Pest-OE/SADG/UI4011/2011. 


\section{REFERENCIAS BIBLIOGRÁFICAS}

AGUDO TORRICO, Juán (2006) "Patrimónios e discursos identitários". En Elsa Peralta y Marta Anico (orgs.) Patrimónios e Identidades. Fiç̧ões Contemporâneas. Oeiras: Celta Editora, pp. 21-34.

APPADURAI, Arjun (2004. or. 1996) Dimensões Culturais da Globalização. Lisboa: Teorema.

AREA, Iván (coord.) (2008) Plan para a salvagarda e posta en valor do patrimonio cultural inmaterial de Galicia. Vigo: Universidad de Vigo.

BENNET, Tony (1995) The Birth of the Museum: History, Theory, Politics. Londres: Routledge.

CASTRO ALLEGUE, Francisco M. (2002) Normativa do patrimonio cultural de Galicia. Santiago de Compostela: Xunta de Galicia.

FERNÁNDEZ DE ROTA, José Antonio (2009) "El giro etnográfico del patrimonio". En Eusebio Medina, Javier Marcos, Martín Gómez-Ullate y David Lagunas (eds.) Fronteras, Patrimonio y Etnicidad en Iberoamérica. Sevilla: Signatura Demos, pp. 155-170.

GONZÁLEZ ALCANTUD, José Antonio (ed.) (2003) Patrimonio y pluralidad. Nuevas direcciones en antropología patrimonial. Granada: Diputación Provincial de Granada.

HANDLER, Richard (1988) Nationalism and the Politics of Culture in Quebec. Madison: University of Wisconsin Press.

LÉVI-STRAUSS, Claude (1992) Antropología Estructural. Barcelona: Paidós.

LLINARES GARCÍA, Mar (2002) "El patrimonio etnográfico inmaterial en la lei do patrimonio cultural de Galicia. Algunas notas (críticas)". Gallaecia 21, pp. 371-392.

MARX, Leo (1964) The Machine in the Garden: Technology and the Pastoral Ideal in America. New York: Oxford University Press.

MEDEIROS, António (2006) Dois lados de um rio. Nacionalismo e Etnografias na Galiza e em Portugal. Lisboa: ICS.

MÉNDEZ, Lurdes (2004) Galicia en Europa. El lugar de las artes plásticas en la política cultural de la Xunta. Sada: Ediciós do Castro.

PAIS DE BRITO, Joaquim (2006) "Patrimónios e identidades. A difícil construção do presente". En Elsa Peralta e Marta Anico (orgs.) Patrimónios e Identidades. Ficções Contemporâneas. Oeiras: Celta Editora, pp. 43- 51.

PENA CASTRO, María Jesús (2006) Vivir na historia. Antropoloxía do patrimonio urbano en Noia. Noia: Toxosoutos. 
PEREIRO, Xerardo (1994) Inventario do patrimonio inmobiliario do Concello de Palas de Rei. Santiago de Compostela: Xunta de Galicia - Sección de Etnografía (inédito).

PEREIRO, Xerardo (1995) Narracións orais do concello de Palas de Rei. Antropoloxía, Lingua e Cultura. Santiago de Compostela: Editorial Sotelo Blanco.

PEREIRO, Xerardo (1999a) “Antropoloxía e Literatura Oral”. ANTROPOlógicas 3, pp. 71-77.

PEREIRO, Xerardo (1999b) "Patrimonialización, museos e arquitectura. O Caso de Allariz”. En Esther Fernández de Paz y Juán Agudo Torrico (coord.) Patrimonio cultural y museología. Significados y contenidos. Actas del VIII Congreso de Antropología del Estado Español, tomo VII. Santiago de Compostela: Asociación Galega de Antropoloxía, pp. $97-110$.

PEREIRO, Xerardo (2001) “Reflexão sobre a antropologia na Galiza de Hoje”. Etnográfica $\mathrm{V}(1)$, pp. 175-183.

PEREIRO, Xerardo y VILAR, Manuel (2002) “Autoimágenes y heteroimágenes en los museos etnográficos gallegos". En Esther Fernández Paz y Silvia Ventosa (coord.) La imagen del otro en el museo. Actas do IX Congreso de Antropología de la FAAEE. Barcelona: ICA (cd-rom), sin paginar.

PEREIRO, Xerardo (2005) Galegos de vila. Antropoloxía dun espazo rurbano. Santiago de Compostela: Editorial Sotelo Blanco.

PEREIRO, Xerardo (2006a) "Patrimonio cultural y riesgos socioculturales". Anuario Etnológico de Andalucía 2002-2003, pp. 419-432.

PEREIRO, Xerardo (2006b) "Património cultural: o casamento entre património e cultura”. ADRA-Revista dos sócios do Museu do Povo Galego 2, pp. 23-41.

PEREIRO, Xerardo (2008) “A produción sociopolítica do património etno-antropolóxico en Galicia”. En Florentino Delgado Ayuso (coord.) III Xornadas sobre a protección do patrimonio cultural. O patrimonio etnográfico. Santiago de Compostela: Xunta de Galicia, pp. 129-141.

PEREIRO, Xerardo (2009) "A lexislación do patrimonio etno-antropolóxico na Galiza: unha vision antropolóxica”. En Xosé Antonio Fidalgo Santamariña; Xosé Manuel Cid et al. (coords.) Patrimonio Etnográfico Galego II. Ourense: Deputación Provincial, pp. 9-14. RODRÍGUEZ CASTRO-RIAL, Romy; SÁNCHEZ RANCAÑO, Cristina y TABOADA ACEVEDO, Rodrigo (1996) Estudio de Construcción Rural en el Camino de Santiago. Palas de Rei. Santiago de Compostela: Xunta de Galicia - Dirección Xeral de Promoción do Camiño de Santiago. 
ROSEMAN, Sharon R. (2008) O rexurdimento dunha base rural no concello de Zas. O Santiaguiño de Carreira. A Coruña: Baía Edicións.

SIERRA RODRÍGUEZ, Xosé Carlos (2000) "O patrimonio etnográfico. Procesos de patrimonialización en Galicia”. En Xosé Manuel González Reboredo (coord.) Galicia. Antropoloxía. A Coruña: Editorial Hércules, pp. 382-470.

SIERRA RODRÍGUEZ, Xosé Carlos (2006) A posta en valor do patrimonio etnográfico. Apuntes breves e reflexión crítica. Ribadavia: Museo Etnológico de Ribadavia (texto inédito).

SMITH, Laurajane (2006) Uses of heritage. Londres: Routledge.

WOLCOTT, Harry F. (1993) "Sobre la intención etnográfica". En Honorio Velasco; Francisco Javier García y Angel Díaz de Rada (eds.) Lecturas de antropología para educadores. Madrid: Trotta, pp. 127-144. 